\title{
Does Thermoplastic Mask Alleivates Skin Sparing Effect of Photons in Head and Neck Cancer Patients: A Pilot study
}

\author{
Puneet Nagpal*, Deep Shankar Pruthi, Prabhakar Shanmugan, Paranthaman Chinnakari, Manish Pandey and \\ Harpreet Singh \\ Department of Radiation Oncology, Action Cancer Hospital, New Delhi, India
}

Submission: December 17, 2020; Published: February 09, 2021

*Corresponding author: Puneet Nagpal, Department of Radiation Oncology, Action Cancer Hospital, New Delhi, India

\begin{abstract}
Introduction: Head and Neck tumors are mainly treated with concurrent chemoradiation. Treatment delivery with Megavoltage beam has the advantage of skin sparing effect but still skin reactions have been a major side effect since 2D era. Initially these reactions were due to the delivery with bilateral opposed portals but with advent of IMRT/ VMAT, it has been possible to escalate the tumor dose with the need of strict immobilization with thermoplastic mask. This thermoplastic mask may have a bolus effect and can result in increase in surface dose resulting in skin reactions. The aim of this study was to evaluate if any bolus effect of thermoplastic mask exists.
\end{abstract}

Materials and Methods: A total of 15 patients of histologically proven carcinoma oropharynx and hypopharynx were taken. Patients were scanned for planning CT with thermoplastic mask. Another scan was taken in the same position but without thermoplastic mask. Same contouring and planning were done on both the scans. Plans were made and ascertained that all OAR's and target volumes should get similar doses. Skin contoured on both the scans was evaluated for the dose received.

Results: Mean dose received by skin in patients with thermoplastic mask was $48.15 \mathrm{GY}$ while Mean dose received by skin in patients without thermoplastic mask was $43.18 \mathrm{GY}$. A paired t-test was applied on the dataset which revealed a statistically significant difference between the skin doses with and without mask with a p value of $<0.05$.

Conclusion: Increase in skin dose can be attributed of the bolus effect of thermoplastic mask. This bolus effect should be considered once high dose to skin is observed during planning or patient develops skin reaction.

Keywords: Thermoplastic mask; Skin sparing effect; Head and neck cancer

\section{Introduction}

Head and Neck Cancers are one of the most common cancers in India [1]. Most of these cancers are treated by Definitive Radiation therapy along with concurrent chemotherapy. Radiation therapy delivered with Megavoltage photon beam on Linear Accelerator has the main advantage of skin sparing effect due to the buildup region, but it still has some major side effects like Radiation Dermatitis and mucositis which depends on volume of the tissue irradiated and dose delivered. The dose distributed to the skin surface is a total of two components, contaminant electrons from treatment head [2] and other caused by secondary electrons produced in the irradiated patient [3]. The number of secondary electrons depends on field size while contaminant electrons depend on field size, beam modifier (Multi Leaf Collimator), the amount of block used and SSD (source to surface distance) $[4,5]$.
Initially, in the 2D era the treatment delivery included two parallel opposed beams with or without lower anterior Neck field which doesn't needed a very strict immobilization, but this treatment was associated with significant skin toxicity [6]. It was difficult to escalate dose to the tumor volume without exceeding the dose to normal structures namely spinal cord, parotids and skin dose. With the advent of IMRT, dose escalation to tumor was possible with controlled OAR doses. It used nonuniform radiation beamlets with computer-controlled treatment planning as well as delivery, but it needed strict immobilization of the patient so as to reproduce the dose distribution achieved during treatment planning at the time of treatment delivery.

The increasing use of IMRT for large targets as seen in H\&N malignancies also resulted in an increase in skin reactions 


\section{Cancer Therapy \& Oncology International Journal}

[7]. Multiple entry and exit of beamlets along with use of rigid immobilization (thermoplastic mask) resulted in increased surface dose. Special thermoplastic mask used to reproducibly position the patient is thought to possibly increase the surface dose to patient and alleviate the skin sparing effect of megavoltage beams [8] as these thermoplastic masks increase the effective patient's skin depth and thus increase the skin dose. IMRT can create hot spots of dose in skin while planning [7] which can be alleviated by the use of VMAT as it causes increase in volume receiving low dose, thus increasing the surface dose in both the techniques [9]. With the use of these conformal techniques and strict immobilization techniques, an early onset and an increase in intensity of skin reactions was noted at our institution. we aim to evaluate in this study that if any increase in skin dose occurs due to the use of these thermoplastic masks.

\section{Methods and Materials}

A total of 15 patients of histologically proven cancer of Head and Neck were included. Patients of carcinoma oropharynx and larynx were preferred, and Post-operative patients were excluded. One patient was excluded from analysis as there was a positional error of more than $0.5 \mathrm{~cm}$ in with mask and without mask scan.
Patients who were included in the study were explained about the procedure and patients willing to participate were included. Patient was taken for planning CT scan where a thermoplastic mask was made by heating it in hot water to a temperature of 6770 degree for $5 \mathrm{~min}$ then it was placed over the face of patient to give the shape of patient. Thermoplastic mask was allowed to dry for 20 minutes and then 3 lead fiducials were applied on the immobilization mask with the help of moving lasers and Planning CT scan was taken. This scan was labelled as "with mask". Care was taken to omit any uneven thickness of thermoplastic mask over the skin or any gaps were avoided. After instructing patient not to move, thermoplastic mask was carefully removed and another scan was taken in this position which was labelled as "without mask". Both scans were imported to the Eclipse Treatment Planning system.

Contouring on both the scans done by a single radiation oncologist with target contours being drawn as GTV, CTV-LR, CTVHR and PTV70, PTV63, PTV56 while all OAR's were drawn on both scans. Skin was drawn on both scans as a brush of $0.6 \mathrm{~cm}$ from the surface. Skin was contoured on the Neck in form of 3 strips of $1 \mathrm{~cm}$ width each at 3 levels (Figure 1):

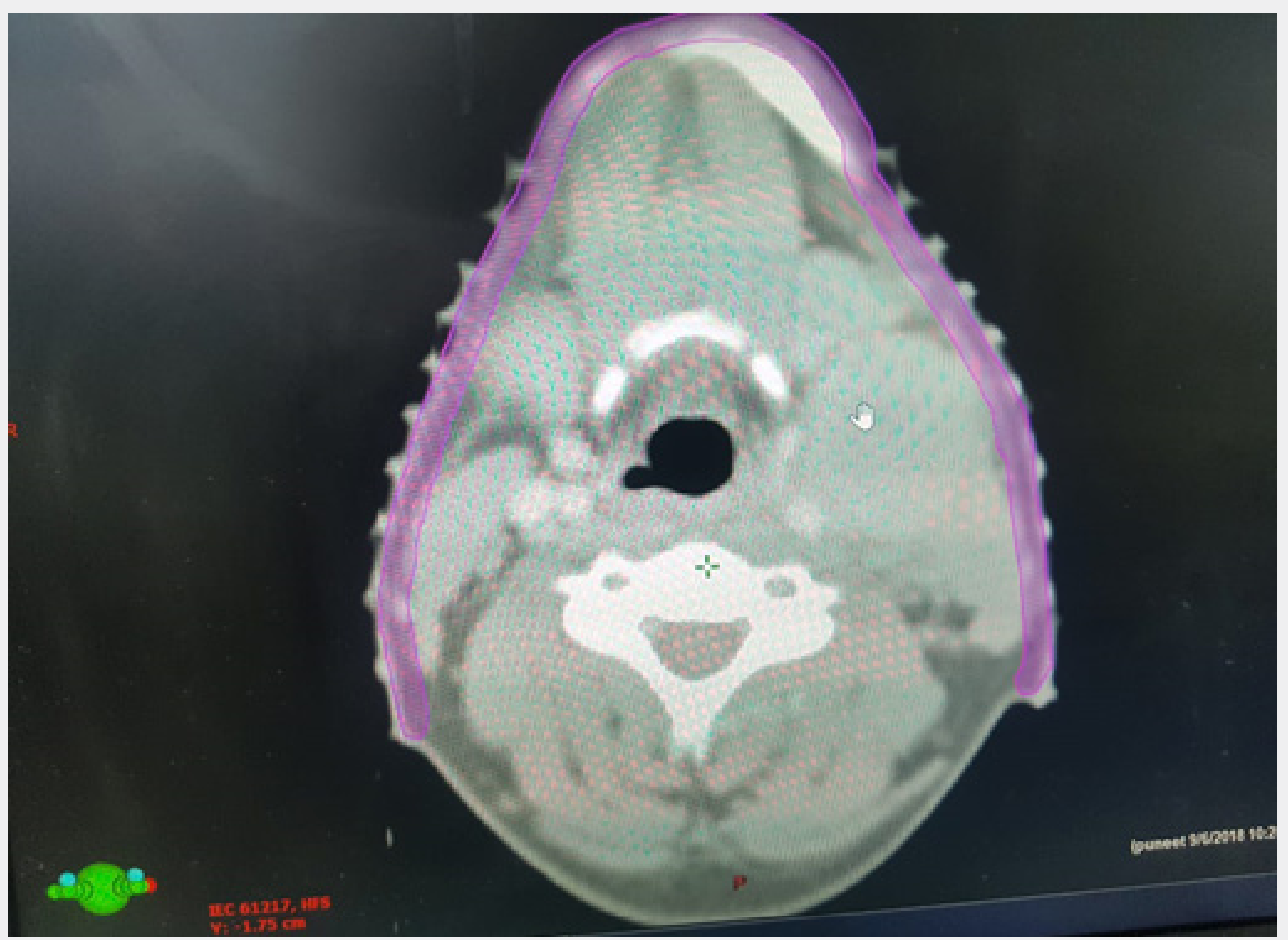

Figure 1: A representative axial section of CT scan showing contouring of skin (shown in pink). 


\section{Cancer Therapy \& Oncology International Journal}

a) At upper neck (between lower most part of mandible and hyoid bone)

b) At mid neck (at the level of thyroid cartilage)

c) At lower neck (below cricoid cartilage)

VMAT plans were made on both the scans. Due care was exercised to keep the target volume and OAR doses similar. If plan made had a difference in doses of target volume or OAR, the plan was revised till the desired results were achieved. After comparing the OAR doses in both the scans, skin dose was calculated in both the scans.

\section{Results}

Mean dose received by skin in patients with thermoplastic mask was 48.15 GY while Mean dose received by skin in patients without thermoplastic mask was $43.18 \mathrm{GY}$. For all the patients, the skin doses in planning CT with mask was consistently higher than the CT without mask. The mean dose increase with usage of mask was 4.27 GY (range 0.86-9.42 Gy) corresponding to an increase of $8.89 \%$ (range 2-20\%). A paired t-test was applied on the dataset which revealed a statistically significant difference between the skin doses with and without mask with a $p$ value of $<0.05$ ( $p$ value 0.000168). Doses to the skin at upper, middle or lower neck was not calculated individually (Table 1). The doses to target volumes as well as OAR'S were kept same in both the plans. The plans were accepted if doses were within $1 \mathrm{GY}$ difference in target volumes and OAR's. Paired t-test was applied individually to mean doses of all OAR's and none of them had statistically significant difference in the doses (Table 2).

Table 1: The difference of skin doses received by the 14 patients with mask or without mask.

\begin{tabular}{|c|c|c|}
\hline & With Thermoplastic Mask & Without Thermoplastic Mask \\
\hline PATIENT 1 & $51.72 \mathrm{GY}$ & $46.75 \mathrm{GY}$ \\
\hline PATIENT 2 & $44.96 \mathrm{GY}$ & $43.28 \mathrm{GY}$ \\
\hline PATIENT 3 & $45.54 \mathrm{GY}$ & $43.37 \mathrm{GY}$ \\
\hline PATIENT 4 & $56.38 \mathrm{GY}$ & $50.38 \mathrm{GY}$ \\
\hline PATIENT 5 & $34.29 \mathrm{GY}$ & $31.18 \mathrm{GY}$ \\
\hline PATIENT 6 & $56.20 \mathrm{GY}$ & $46.78 \mathrm{GY}$ \\
\hline PATIENT 7 & $46.37 \mathrm{GY}$ & $39.41 \mathrm{GY}$ \\
\hline PATIENT 8 & $43.67 \mathrm{GY}$ & $40.98 \mathrm{GY}$ \\
\hline PATIENT 9 & $54.82 \mathrm{GY}$ & $45.30 \mathrm{GY}$ \\
\hline PATIENT 10 & $52.77 \mathrm{GY}$ & $49.40 \mathrm{GY}$ \\
\hline PATIENT 11 & $44.20 \mathrm{GY}$ & $42.49 \mathrm{GY}$ \\
\hline PATIENT 12 & $47.00 \mathrm{GY}$ & $42.43 \mathrm{GY}$ \\
\hline PATIENT 13 & $45.74 \mathrm{GY}$ & $44.88 \mathrm{GY}$ \\
\hline PATIENT 14 & $50.50 \mathrm{GY}$ & $47.60 \mathrm{GY}$ \\
\hline
\end{tabular}

Table 2: The mean doses to various OAR's and target volumes in both plans.

\begin{tabular}{|c|c|c|c|}
\hline Structure & With Thermoplastic mask & Without thermoplastic mask & P Value \\
\hline Brainstem & 36.73 & 36.2 & 0.272 \\
\hline Left cochlea & 18.47 & 17.5 & 0.292 \\
\hline Right cochlea & 10.81 & 9.99 & 0.118 \\
\hline Lips & 25.21 & 24.67 & 0.239 \\
\hline Mandible & 67.87 & 68.06 & 0.518 \\
\hline Left Parotid & 38.95 & 38.99 & 0.902 \\
\hline Right Parotid & 28.38 & 28.58 & 0.706 \\
\hline Spinal cord & 37.27 & 37.38 & 0.584 \\
\hline D95 PTV70 & 67.86 & 67.62 & 0.5 \\
\hline D95 PTV60 & 59.51 & 59.48 & 0.776 \\
\hline D95 PTV54 & 53.59 & 53.47 & 0.199 \\
\hline
\end{tabular}




\section{Cancer Therapy \& Oncology International Journal}

\section{Discussion}

Radiation dermatitis or skin reactions can be divided into acute and chronic [10]. Acute skin reactions are those occurring during the radiation therapy phase and can continue up to 2-3 weeks post radiation. Chronic skin reactions occur late usually after 5 years and mainly depends on total dose (dose given and volume irradiated) accumulated in skin. Acute skin reactions are divided into 4 stages [11]:
a) Erythema
b) Dry Desquamation
c) Moist Desquamation
d) Necrosis/ Ulceration

Acute skin reactions usually start in $3^{\text {rd }}$ to $4^{\text {th }}$ week during radiation therapy and usually depends on total dose received by skin and volume of skin irradiated. Ortho voltage beams [12] and electron beams [13] don't have skin sparing effect, so result in early development of skin reactions. This resulted in inability to escalate radiation dose to tumoricidal doses but with the advent of mega voltage radiation, skin sparing had been possible. Initially Mega Voltage radiation was delivered with parallel opposed bilateral portals in Head and Neck tumors which usually resulted in Grade 3 skin reactions in approximately $25 \%$ of cases [14]. It has been estimated that skin ulceration will occur in $5 \%$ of the patients when the skin receives 55 Gy and in $50 \%$ of those who receive 70 Gy with megavoltage irradiation. Tolerance dose for skin reactions within 5 years in $5 \%$ of patients receiving 55 Gy to an area of skin $10 * 10 \mathrm{~cm}$ (tolerance dose with $5 \%$ complication rate within 5 years, TD5/5) and in $50 \%$ of patients receiving 70 Gy (TD50/5) [15,16].

But with the use of IMRT / VMAT, dose escalation has been done with improvement in local control of disease [17] as well as sparing of OAR'S but it needed strict immobilization for exact reproducibility and hence rigid immobilization with thermoplastic mask. The use of this mask also results in increase in skin dose as cited in literature [17] which is comparable to our results. This increase in skin dose can be attributed to multiple reasons. Firstly, it can be due to the bolus effect of thermoplastic mask as it has been published in literature that thermoplastic mask reduces the buildup region of megavoltage radiation and hence increases surface dose [18]. The increase of surface dose depends on thickness of material used and holes in the mask. Thermoplastic mask to be used should be evenly stretched and thinned out as well it should have larger holes to minimize its bolus effect Second reason for increase in skin doses can be attributed to how one has contoured the neck nodes as well as size and proximity of neck nodes to skin.

In this study we have tried to reduce contouring bias by single radiation oncologist contouring all targets and OAR's and single physicist making the plans. Both the Plans were made similar as well as comparable to each other so that planning bias can be omitted. Clinical implication of this study was that immobilization mask has some bolus effect on the skin but the increase in skin dose due to this can be attributed to other factors also. Moreover, the benefits attained in reduction of margins by strict immobilization also contributes indirectly in reducing the surface dose. All the patients in the study were treated with thermoplastic mask and VMAT technique and mask was cut at the areas of high doses to skin after development of Grade 2 skin reactions to alleviate the bolus effect.

The main limitation of the study was the calculation of skin dose. This calculation was done by the treatment planning software but the exact dose at the time of treatment delivery was not calculated in vivo. Three methods could be used to record real time dose received by skin at the time of treatment delivery. The most accurate being in-vivo dosimetry [19], second being Thermoluminescent Dosimetry [20] and lastly being Film dosimetry [21]. All these techniques can be used to verify the skin dose difference postulated and hence the bolus effect of mask as evaluated in the study, but these Quality Assurance techniques and apparatus are very much limited. Lastly, though due precautions were kept in making the contour and plans same in both the scan, but some variations might be there to result in dose calculation difference in skin dose which can be verified with QA techniques enumerated above.

\section{Conclusion}

Increase in skin dose can be attributed of the bolus effect of thermoplastic mask. This bolus effect should be considered once high dose to skin is observed during planning or patient develops skin reaction. Other factors can also result in increase in skin dose, but effort has been made to keep them uniform in the study.

\section{References}

1. Mohanti BK, Nachiappan P, Pandey RM, Sharma A, Bahadur S, et al. (2007) Analysis of 2167 head and neck cancer patients' management, treatment compliance and outcomes from a regional cancer centre, Delhi, India. J Laryngol Otol 121(1): 49-56.

2. Beauvais H, Bridier A, Dutreix A (1993) Characteristics of contamination electrons in high energy photon beams. Radiother Oncol 29(3): 308-316.

3. Nizin PS (1993) Electronic equilibrium and primary dose in collimated photon beam. Med Phys 20(6): 1721-1729.

4. Klein EE, Purdy JA (1993) Entrance and exit dose regions for a Clinac2100C. Int J Radiat Oncol, Biol Phys 27(2): 429-435.

5. McParland PJ (1991) The effects of a universal wedge and beam obliquity upon the central axis dose buildup for 6-MV x-rays. Med Phys 18(4): 740-743.

6. Eisbruch A, Ship JA, Martel MK, Ten Haken RK, Marsh LH, et al. (1996) Parotid gland sparing in patients undergoing bilateral head, and neck irradiation: Techniques and early results. Int J Radiat Oncol Biol Phys 36(2): 469-480. 
7. Lee N, Chuang C, Quivey JM, Phillips TL, Akazawa P, et al. (2002) Skin toxicity due to intensity-modulated radiotherapy for head-and-neck carcinoma. Int J Radiat Oncol Biol Phys 53(3): 630-637.

8. Chiu Tsao S, Sim S, Chan MF (2008) The impact of patient immobilization devices on skin dose during IMRT: a radiochromic EBT film dosimetry study in phantom. Int J Radiat Oncol Biol Phys 72(1): S659.

9. Wiezorek T, Brachwitz T, Dietmar G, Schubert K, Wagner D, et al. (2011) Rotational IMRT techniques compared to fixed gantry IMRT and tomotherapy: Multi-Institutional planning study forhead-andneckcases. Radiat Oncol 6: 20.

10. Fajardo LF (1982) Skin. Masson monographs in diagnostic pathology. In: Sternberg SS, editor. New York: Masson Publishing 6: 186-215.

11. Brunst VV (1963) The successive changes in the skin epithelium of the young axolotl after roentgen irradiation. AJR Am J Roentgenol 89: 624647

12. Liegner LM, Michaud NJ (1961) Skin and subcutaneous reactions induced by supervoltage irradiation. AJR Am J Roentgenol 85: 533-549.

13. Price N (1978) Radiation dermatitis following electron beam therapy. Arch Dermatol 114(1): 63-66.

14. Bahl A, Oinam A, Kaur S, Verma R, Elangovan, et al. (2017) Evaluation of Acute Toxicity and Early Clinical Outcome in Head and Neck Cancers Treated with Conventional Radiotherapy and Simultaneous Integrated Boost Arc Radiotherapy. World Journal of Oncology, North America 8(4): 117-121.
15. Emami B, Lyman J, Brown A, Goitein M, Munzenrider JE, et al. (1991) Tolerance of normal tissue to therapeutic irradiation. Int J Radiat Oncol Biol Phys 21(1): 109-122.

16. Turesson I, Notter G (1979) The response of pig skin to single and fractionated high dose-rate and continuous low dose-rate Cs- 137 irradiation-I: Experimental design and results. Int J Radiat Oncol Biol Phys 5(6): 835-844.

17. Guerrero UT, Catharine HC, Vibeke NH, Elizabeth JA, Roger AH, et al. (2007) A phase I study of dose-escalated chemoradiation with accelerated intensity modulated radiotherapy in locally advanced head and neck cancer. Radiother Oncol 85(1): 36-41.

18. Hadley SW, Robin K, Kwok L (2005) Effects of immobilization mask material on surface dose. J Appl Clin Med Phys 6(1): 1-7.

19. Mohammadi M, Haghparast A, Zaghian R (2018) Skin In vivo Dosimetry in Radiotherapy. 15(12).

20. Ostwald PM, Kron T, Hamilton CS, Denham JW (1995) Clinical use of carbon-loaded thermoluminescent dosimeters for skin dose determination. Int J Radiat Oncol Biol Phys 33(4): 943-950.

21. Devic S, Seuntjens J, Abdel Rahman W, Evans M, Olivares M, et al (2006) Accurate skin dose measurements using radiochromic film in clinical applications. Med Phys 33(4): 1116-1124.

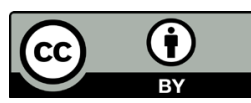

This work is licensed under Creative Commons Attribution 4.0 License DOI:10.19080/CTOIJ.2021.18.555978
Your next submission with Juniper Publishers will reach you the below assets

- Quality Editorial service

- Swift Peer Review

- Reprints availability

- E-prints Service

- Manuscript Podcast for convenient understanding

- Global attainment for your research

- Manuscript accessibility in different formats ( Pdf, E-pub, Full Text, Audio)

- Unceasing customer service

Track the below URL for one-step submission https://juniperpublishers.com/online-submission.php 